\title{
Statins in High-Risk Chronic Obstructive Pulmonary Disease Outpatients: No Impact on Time to First Exacerbation and All-Cause Mortality - The STATUETTE Cohort Study [Corrigendum]
}

Damkjær M, Håkansson K, Kallemose T, Ulrik CS, Godtfredsen N. Int J Chron Obstruct Pulmon Dis. 2021;16:579-589.

The authors have advised that the statistical analysis script incorrectly labelled patients receiving ICS/LABA- combination inhalers as only receiving LABA. The error has resulted in an incorrect prevalence of ICS treatment in Table 1 on page 583 (7\% instead of the correct $55 \%$ ) as well as some changes in regression covariable estimates in Table 2 on page 584. The correct Tables 1 and 2 are shown below.

Table I Demographics of 950 COPD Patients, Divided by Statin Treatment Status, at a University Hospital Outpatient Clinic

\begin{tabular}{|c|c|c|c|c|}
\hline & Total, $\mathbf{N}=950^{a}$ & Statin Users, $N=393^{\mathrm{a}}$ & Non-Users, $\mathbf{N}=557^{\mathrm{a}}$ & p-value ${ }^{b}$ \\
\hline Male (sex) & 448 (47\%) & 207 (53\%) & $24 I(43 \%)$ & 0.005 \\
\hline Age & $71(11)$ & $73(9)$ & $69(11)$ & $<0.001$ \\
\hline BMI & $25.5(5.8)$ & $26.3(5.5)$ & $24.9(5.9)$ & $<0.001$ \\
\hline History of smoking & & & & 0.701 \\
\hline Current smoker & $247(26 \%)$ & 101 (26\%) & 146 (26\%) & \\
\hline Ex. smoker & 665 (70\%) & $279(71 \%)$ & 386 (69\%) & \\
\hline Never-smoker & 37 (3.9\%) & $13(3.3 \%)$ & $24(4.3 \%)$ & \\
\hline Missing values & I & I & 0 & \\
\hline Pack years of smoking & $43(30,51)$ & $45(32,55)$ & $40(30,50)$ & $<0.001$ \\
\hline Missing values & 74 & 26 & 48 & \\
\hline FEVI\%pred & $44(33,57)$ & $45(35,60)$ & $43(31,56)$ & 0.015 \\
\hline Missing values & I & 0 & I & \\
\hline GOLD stage I-4 & & & & 0.137 \\
\hline GOLD I & 39 (4.1\%) & $19(4.8 \%)$ & $20(3.6 \%)$ & \\
\hline GOLD 2 & $332(35 \%)$ & 149 (38\%) & $183(33 \%)$ & \\
\hline GOLD 3 & $392(41 \%)$ & $162(41 \%)$ & $230(41 \%)$ & \\
\hline GOLD 4 & $186(20 \%)$ & $63(16 \%)$ & $123(22 \%)$ & \\
\hline MRC & $3.30(1.21)$ & $3.33(1.16)$ & $3.28(1.25)$ & 0.633 \\
\hline Missing values & II & 6 & 5 & \\
\hline History of severe exacerbations (previously) & $211(22 \%)$ & $89(23 \%)$ & $122(22 \%)$ & 0.848 \\
\hline GOLD A-D groups & & & & 0.626 \\
\hline A & $219(24 \%)$ & $83(22 \%)$ & $136(26 \%)$ & \\
\hline B & $308(34 \%)$ & $134(35 \%)$ & $174(33 \%)$ & \\
\hline C & 57 (6.3\%) & $24(6.3 \%)$ & $33(6.2 \%)$ & \\
\hline $\mathrm{D}$ & $327(36 \%)$ & $138(36 \%)$ & $189(36 \%)$ & \\
\hline Missing values & 39 & 14 & 25 & \\
\hline
\end{tabular}


Table I (Continued).

\begin{tabular}{|c|c|c|c|c|}
\hline & Total, $\mathbf{N}=950^{\mathrm{a}}$ & Statin Users, $N=393^{a}$ & Non-Users, $\mathbf{N}=557^{\mathrm{a}}$ & p-value \\
\hline \multicolumn{5}{|l|}{ Comorbidities } \\
\hline Atrial fibrillation & 157 (I7\%) & $82(21 \%)$ & $75(13 \%)$ & 0.003 \\
\hline Hypertension & 469 (49\%) & $266(68 \%)$ & $203(36 \%)$ & $<0.001$ \\
\hline Stable ischemic heart disease & $79(8.3 \%)$ & $67(17 \%)$ & $12(2.2 \%)$ & $<0.001$ \\
\hline History of ACS & $59(6.2 \%)$ & 49 (12\%) & $10(1.8 \%)$ & $<0.001$ \\
\hline Diabetes type I or II & 140 (I5\%) & $110(28 \%)$ & $30(5.4 \%)$ & $<0.001$ \\
\hline History of stroke & 102 (II\%) & $77(20 \%)$ & $25(4.5 \%)$ & $<0.001$ \\
\hline Congestive heart failure & $76(8.0 \%)$ & $53(13 \%)$ & $23(4.1 \%)$ & $<0.001$ \\
\hline Cancer (any type) & $128(13 \%)$ & $56(14 \%)$ & $72(13 \%)$ & 0.623 \\
\hline Peripheral vascular disease & $57(6.0 \%)$ & 44 (1 I\%) & $13(2.3 \%)$ & $<0.001$ \\
\hline Osteoporosis & $24 I(25 \%)$ & 101 (26\%) & $140(25 \%)$ & 0.903 \\
\hline Concomitant asthma & 176 (19\%) & $58(15 \%)$ & 118 (21\%) & 0.015 \\
\hline Total cholesterol (mM) & $4.62(1.62)$ & $4.98(1.07)$ & $4.23(1.12)$ & $<0.001$ \\
\hline Missing values & 196 & 32 & 164 & \\
\hline Single bronchodilator (LABA or LAMA) & $818(86 \%)$ & $332(84 \%)$ & $486(87 \%)$ & 0.223 \\
\hline Dual bronchodilators (LABA and LAMA) & $260(27 \%)$ & $154(28 \%)$ & $106(27 \%)$ & 0.876 \\
\hline ICS & $520(55 \%)$ & $198(50 \%)$ & $322(58 \%)$ & 0.023 \\
\hline
\end{tabular}

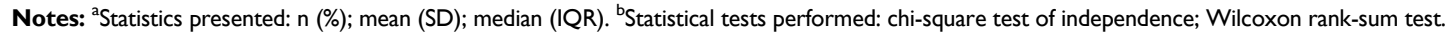

Abbreviations: LABA, long-acting beta2-agonist; LAMA, long-acting muscarinic antagonist; ICS, inhaled corticosteroids; ACS, acute coronary syndrome; BMI, Body Mass Index; GOLD, Global Initiative for Chronic Obstructive Lung Disease; FEVI\%pred, predicted forced expiratory volume in one second; MRC, Medical Research Council score.

Table 2 A Time-Varying Covariate Cox Proportional Hazard Regression for Association of Statin Use and Hazard Ratio (HR) for Time to First Exacerbation in 950 COPD High-Risk Outpatients

\begin{tabular}{|c|c|c|c|c|c|c|c|c|c|}
\hline & \multicolumn{3}{|c|}{ Crude } & \multicolumn{3}{|c|}{ Adjusted } & \multicolumn{3}{|c|}{ Interaction CVD } \\
\hline & HR & $95 \% \mathrm{Cl}$ & p-value & HR & $95 \% \mathrm{Cl}$ & p-value & HR & $95 \% \mathrm{Cl}$ & p-value \\
\hline Statin use & 1.10 & $0.92,1.32$ & 0.276 & 1.16 & $0.97,1.41$ & 0.108 & 1.14 & $0.88,1.49$ & 0.359 \\
\hline Age & & & & 1.02 & $1.01,1.03$ & $<0.001$ & 1.02 & $1.01,1.03$ & $<0.001$ \\
\hline \multicolumn{10}{|l|}{ Sex } \\
\hline Male & & & & 1 & & & 1 & & \\
\hline Female & & & & 1.09 & $0.91,1.30$ & 0.371 & 1.09 & $0.91,1.31$ & 0.330 \\
\hline Congestive heart failure & & & & 1.03 & $0.75,1.4 \mathrm{I}$ & 0.858 & 1.02 & $0.74,1.40$ & 0.924 \\
\hline BMI & & & & 0.99 & $0.97, \sim 1.00$ & 0.075 & 0.98 & $0.97,1.00$ & 0.065 \\
\hline \multicolumn{10}{|l|}{ GOLD I-4 stage } \\
\hline GOLD I & & & & 1 & & & 1 & & \\
\hline GOLD 2 & & & & 3.57 & $1.45,8.77$ & 0.006 & 3.54 & $|.44,8.7|$ & 0.006 \\
\hline GOLD 3 & & & & 5.36 & $2.19,13.1$ & $<0.001$ & 5.32 & $2.17,13.0$ & $<0.001$ \\
\hline GOLD 4 & & & & 8.91 & $3.6 \mathrm{I}, 22.0$ & $<0.001$ & 8.86 & $3.59,21.9$ & $<0.001$ \\
\hline LABA or LAMA & & & & 0.98 & $0.74,1.29$ & 0.869 & 0.98 & $0.74,1.29$ & 0.883 \\
\hline LABA and LAMA & & & & 1.04 & $0.82,1.32$ & 0.792 & 1.05 & $0.83,1.33$ & 0.826 \\
\hline ICS & & & & 1.45 & $1.15,1.84$ & 0.002 & 1.45 & $1.15,1.84$ & 0.002 \\
\hline Cardiovascular disease & & & & & & & 1.09 & $0.79,1.53$ & 0.592 \\
\hline Statin use* Cardiovascular disease & & & & & & & 0.97 & $0.62,1.50$ & 0.879 \\
\hline
\end{tabular}

Note: The analysis was stratified for smoking status.

Abbreviations: HR, hazard ratio; $\mathrm{Cl}$, confidence interval; BMI, body mass index; GOLD, Global Initiative for Chronic Obstructive Lung Disease severity staging; LABA, long-acting beta2-agonist; LAMA, long-acting muscarinic antagonist; ICS, inhaled corticosteroids. 
Page 579, Abstract, Results section, the text "When stratifying for moderate and severe exacerbations in a subanalysis in the same model, statin use did not have an increased $\mathrm{HR}$ for exacerbation of either severity $(\mathrm{HR}=$ $1.02(95 \%$ CI 0.85 to $1.24 ; \mathrm{p}=0.811)$ and $\mathrm{HR}=1.07(95 \%$ CI 0.89 to $1.29 ; \mathrm{p}=0.492$ ) respectively)" should read "When stratifying for moderate and severe exacerbations in a sub-analysis in the same model, statin use did not have an increased HR for exacerbation of either severity (HR = $1.02(95 \%$ CI 0.85 to $1.23 ; \mathrm{p}=0.812)$ and $\mathrm{HR}=1.07(95 \%$ CI 0.89 to $1.29 ; \mathrm{p}=0.457$ ) respectively)".

Page 584, right column, second paragraph, the text "When stratifying for moderate and severe exacerbations in a sub- analysis in the same model, statin use was not to reduced time to AECOPD for either severity (HR $=1.02(95 \% \mathrm{CI}$ 0.85 to $1.24 ; \mathrm{p}=0.811)$ and $\mathrm{HR}=1.07$ (95\% CI 0.89 to $1.29 ; \mathrm{p}=0.492)$ respectively)" should read "When stratifying for moderate and severe exacerbations in a subanalysis in the same model, statin use was not to reduced time to AECOPD for either severity (HR $=1.02(95 \% \mathrm{CI}$ 0.85 to $1.23 ; \mathrm{p}=0.812)$ and $\mathrm{HR}=1.07(95 \% \mathrm{CI} 0.89$ to $1.29 ; \mathrm{p}=0.457$ ) respectively)".

The authors apologize for the error and advise the prevalence and regression analyses does not change the conclusions of the paper nor does it affect the presented main outcomes of the study.

\section{Publish your work in this journal}

The International Journal of COPD is an international, peer-reviewed journal of therapeutics and pharmacology focusing on concise rapid reporting of clinical studies and reviews in COPD. Special focus is given to the pathophysiological processes underlying the disease, intervention programs, patient focused education, and self management protocols. This journal is indexed on PubMed Central, MedLine and CAS. The manuscript management system is completely online and includes a very quick and fair peer-review system, which is all easy to use. Visit http://www.dovepress.com/testimonials.php to read real quotes from published authors. 